\title{
Climate, nitrogen and grass. 5. Influence of age, light intensity and temperature on the production and chemical composition of Congo grass (Brachiaria ruziziensis Germain et Everard)
}

\author{
B. Deinum and J. G. P. Dirven \\ Department of Field Crops and Grassland Husbandry, Wageningen, the Netherlands
}

Received: 15 February 1972

\section{Summary}

Age, light intensity and temperature significantly affected morphological characters and chemical composition of Congo grass.

A longer growing period showed a higher dry-matter production, due to a small increase in tiller number and a great increase in tiller weight. This increase in tiller weight caused a decrease in $\%$ leaf, $\%$ organic nitrogen and ash, and an increase in $\%$ crude fibre of stems; age did not affect $\%$ crude fibre of leaves.

A higher light intensity caused a higher dry matter production as well, because of a sharp increase in tiller number; average tiller weight was not affected, nor $\%$ leaf and $\%$ organic nitrogen. Light intensity showed a direct negative effect on $\%$ nitrate nitrogen, ash and on $\%$ crude fibre of leaf and stem.

A higher temperature increased dry-matter production, caused by a decrease in tiller number and a sharp increase in tiller weight. The latter was associated with a decrease in $\%$ leaf and $\%$ organic nitrogen and an increase in $\%$ crude fibre. In addition temperature had a direct positive effect on $\%$ crude fibre of leaves and stems causing poor quality forage in warm climates.

Results indicated that light intensity and temperature affect forage quality partly by effects on morphological composition and partly by direct effects on the composition of the separate morphological fractions.

\section{Introduction}

The nutritive value of forage grasses is quite variable, as affected by age, grass species and fertilization, and also by the climate in which grass is growing (Alberda, 1965; Deinum, 1966a; Deinum et al., 1968). From this work is is evident that digestibility of dry matter measured directly or estimated from the percentage of crude fibre was not much affected by light intensity, but was appreciably decreased by higher temperature. These effects were so consistent in many experiments that it was attractive to extrapolate these data obtained on temperate grasses to other climates. Using this extrapolation for areas with high temperatures the low nutritive value of tropical grass could almost be predicted (Deinum, 1966a; 1966b).

In order to investigate how far this extrapolation was justified and whether the hypothesis that tropical grasses have a low digestibility because of the high temperature was correct, a series of experiments was carried out with tropical grasses. Results of a 
preliminary experiment with Brachiaria ruziziensis proved again that high temperature had an adverse effect on digestibility (Deinum and Dirven, 1967).

However, most of the earlier work of Deinum had been done with Lolium perenne in a vegetative stage and in this stage climate has not much effect on the development of the grass, but the preliminary work on Congo grass (Deinum and Dirven, 1967) demonstrated that plant development and stem formation were influenced by climate. This implies that in a detailed study of the effect of environmental factors on forage quality of tropical grasses, more attention should be paid to the effect of environmental conditions on the morphological development of the grass. To this purpose a more elaboratc experiment was carried out in which the effect of age, light intensity and temperature on the tropical grass species Congo grass was investigated.

\section{Material and methods}

On 11 March 1965, 13 tillers of Congo grass (Brachiaria ruziziensis Germain et Everard, originating from Zaire) were planted in 5-litre plastic pots ( $3 \mathrm{dm}^{2}$ surface) filled with well fertilized sandy soil and allowed to regrow under favourable conditions in a greenhouse with some clippings in between to promote tillering. The experiment started on 12 May when the pots were distributed over three greenhouses with three light intensities, and arranged with 12 pots per $\mathrm{m}^{2}$.

The three temperatures in the greenhouses to be realized were $23 / 18,28 / 23$ and $33 / 28$ day and night temperatures in ${ }^{\circ} \mathrm{C}$, respectively, but the temperatures measured during the experiment were $24 / 19,28 / 24.5$ and $33 / 25^{\circ} \mathrm{C}$ indicated as $\mathrm{T}_{1}, \mathrm{~T}_{2}$ and $\mathrm{T}_{3}$. Average relative humidity in all three temperature treatments was about $70 \%$ during the day' and $80 \%$ at night. The three light intensities were:

$\mathrm{L}_{1}$ : low light intensity: average $160 \mathrm{cal} \mathrm{cm}^{-2}$ day-1 by shading with cheese cloth

$\mathrm{L}_{2}$ : normal light intensity: average $279 \mathrm{cal} \mathrm{cm}^{-2} \mathrm{day}^{-1}=80 \%$ of total daily radiation

Ls: high light intensity: average $621 \mathrm{cal} \mathrm{cm}^{-2}$ day $^{-1}=\mathrm{L}_{2}+342 \mathrm{cal} \mathrm{cm}^{-2} \mathrm{day}^{-1}$ artificial light during day time from Philips HPLR-400 W mercury lamps.

Day length was 15-16 hours. Pots were fertilized with nitrogen and macro + microminerals dissolved in water on 12 May and again with nitrogen and macrominerals on 28 May and 4 June. All tillers were marked with pigeon rings at the beginning of the experiment and allowed to regrow.

On the cutting dates after 2,3,4 and 5 weeks regrowth, 8 pots per treatment were clipped and old and newly formed tillers separated. The herbage was immediately weighed and dried in a forced draft oven and later on seperated into leaf lamina and leaf sheath + stem, ground and prepared for chemical analysis.

The leaf and stem fractions were analysed for crude fibre content if sufficient material was available and the bulked samples were analysed for $\%$ total nitrogen ( $\%$ total $\mathrm{N}$ ), $\%$ nitrate-nitrogen $\left(\% \mathrm{NO}_{3}-\mathrm{N}\right), 0 \%$ ash, $\%$ water-soluble carbohydrates $(\%$ wsc) and $\%$ crude fibre $(\% \mathrm{cf}) ; \%$ rest $(\% \mathrm{r})$ was calculated as the difference between $\%$ nitrogenfree extract and $\%$ wsc.

The experiment was set up as a split-plot design in which the effect of temperature was tested against the interaction of temperature $x$ age.

\section{Results and discussion}

The major results are presented in Table 1 , in which the main effects have been quantified. 
CI.IMATE, NITROGEN AND GRASS. 5

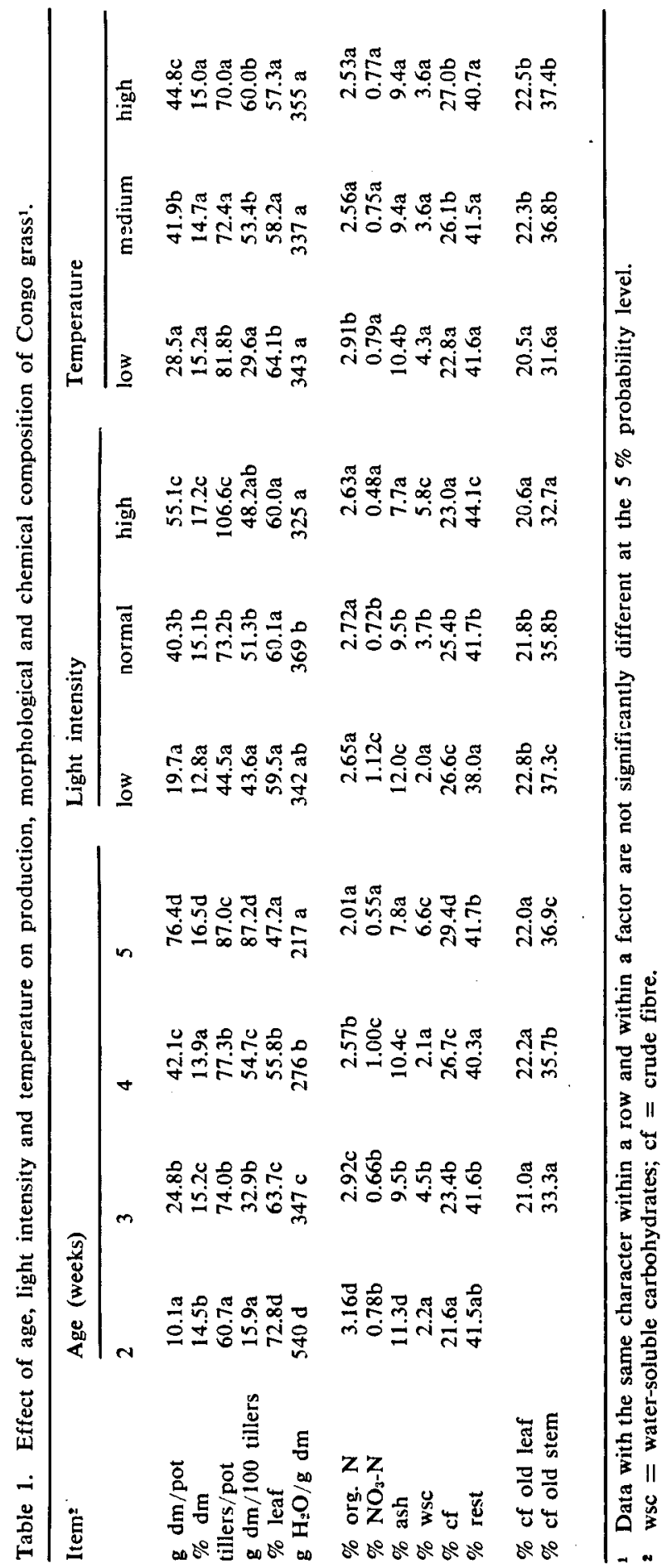

Neth. J. agric. Sci. 20 (1972) 


\section{Morphological characters}

Dry-matter yield. Table 1 shows that dry-matter yield increased with increasing age, light intensity and temperature. The difference between $T_{2}$ and $T_{3}$ was very small, possibly because both temperatures were close to the optimum temperature for growth. There appeared to be an interaction between light intensity and temperature presumably because of the somewhat higher temperature of the $T_{1} L_{3}$ treatments due to the mercury lamps.

Percentage of dry matter. The percentage of dry matter was appreciably increased by higher light intensity. Age also seemed to show some effect, but this was so closely related to the percentage of $\mathrm{NO}_{3}-\mathrm{N}$, that it was certainly caused by the varying supply of nitrogen due to the addition of nutrients during the experiment. The old tillers showed a somewhat higher $\%$ dry matter than the new tillers; the average difference being $0.3 \%$ unit.

Number of tillers. There were about 40 tillers present per pot at the start of the experiment. This number remained almost constant at low light intensity, but was considerably increased by higher light intensity, especially with a longer growth period. Furthermore, new tillering was stimulated by low temperatures, the $\mathrm{T}_{1} \mathrm{~L}_{3}$ treatment showing the highest tiller number (144) after 5 weeks. This effect seems contradictory to the findings of Wilson and Ford (1971) in the tropical grasses Panicum maximum var. trichoglume and Setaria sphacelata $c v$. 'Nandi', but this may have been caused by the experimental technique; they started from seedlings whose growth was progressively stimulated by higher temperatures, whereas in this experiment we started with a small sward. However, our findings agree with those of earlier experiments with small swards of perennial ryegrass (Deinum, 1966a) and Congo grass (Deinum and Dirven, 1967).

Tiller weight. Tiller weight increased considerably with age and temperature. Light intensity did not show much effect on the average tiller weight. This was caused by the presence of an increasing number of new lighter tillers at higher light intensities, Light intensity in fact stimulated tiller weight of old and new tillers separately. In the same way tiller weight was low at low temperatures, because of the low weight of old and new tillers and the large proportion of new tillers. An example of how the same drymatter yield may be achieved with different numbers and weights of tillers is shown in Table 2, which mentions the yields of the $T_{3} L_{2}$ and $T_{1} L_{3}$ treatments after 5 weeks. In this experiment tillers elongated appreciably up to a length of $1 \mathrm{~m}$, but did not yet flower. At a shorter day length inflorescence development would have been stimulated (Deinum and Dirven, 1967, unpublished data).

Table 2. Yield and tiller number and weight of two different treatments after 5 weeks regrowth.

\begin{tabular}{llcl}
\hline Treatment & g dm/pot & tillers $/$ pot & g dm/100 tillers \\
T:Ls & 104.9 & 82 & 128 \\
T:Ls & 104.4 & 144 & 73 \\
\hline
\end{tabular}


Percentage leaf. Percentage leaf appeared to be closely related to tiller weight. It decreased with age from 73 to $47 \%$ and with higher temperature; it was not affected by light intensity. However, there was a significant interaction between light intensity and age, showing higher $\%$ leaf at high light intensity after 2 weeks growth and lower $\%$ after 5 weeks growth, both in old and new tillers. The interaction between light intensity and temperature was also significant, showing at $T_{1}$ the lowest $\%$ leaf at $L_{s}$ and at $T_{3}$ the highest at $\mathrm{L}_{8}$ which was associated again with tiller weight.

New tillers had a somewhat higher $\%$ leaf than the old tillers; the average difference being about $8 \%$ unit.

Water consumption. Water consumption per gramme $\mathrm{dm}$ of herbage decreased with age due to the decreasing $\%$ leaf. If calculated on the basis of dry weight of leaf this decreasing effect almost disappeared. Light intensity and temperature did not show a significant effect on water consumption. Although not significant the interaction of light intensity and temperature was parallel to the effect on $\%$ leaf. Considering fresh weight of leaf as an estimate of the transpiring area and assuming $\%$ dry matter of leaf and stem equal which is justified within some limits, water consumption per gramme fresh leaf showed some decrease with age and an increase with higher light intensity and temperature.

\section{Chemical composition}

Percentage organic nitrogen. Percentage of organic nitrogen $(0 \%$ org. $\mathrm{N}=0 \%$ total- $\mathrm{N}$ minus $\% \mathrm{NO}_{3}-\mathrm{N}$ ) decreased appreciably with age, whereas it was also decreased by increasing temperature. Light intensity did not show a significant effect. It was found that $\%$ org. $\mathrm{N}$ reacted parallel to $\%$ leaf to the different environmental factors, suggesting that $\%$ leaf was the major factor determining $\%$ org. N. No effect of the varying supply of nitrogen on $\%$ org. $\mathrm{N}$ could be detected, suggesting that nitrogen supply was always adequate in this experiment.

Percentage nitrate nitrogen. This concentration was considerably decreased by higher light intensity as was found before in experiments with other grasses (Deinum, 1966a). Temperature showed no effect in this experiment, but age did, certainly due to the varying supply of nitrogen. The nitrate content was usually very high in this grass species, well above the limit of $0.15 \% \mathrm{NO}_{3}-\mathrm{N}$ for perennial ryegrass (van Burg, 1962) and of $0.10 \% \mathrm{NO}_{3}-\mathrm{N}$, for Italian ryegrass (Hylton et al., 1964).

Percentage ash. This concentration was appreciably decreased by higher light intensity and somewhat by higher temperature, the latter possibly related to the percentage of leaves. At low light intensity $\%$ ash did not decrease with higher temperature, but at higher light intensity it did. There was some effect of age, but the parallel with $\%$ $\mathrm{NO}_{3}-\mathrm{N}$ was so close that there must be a definite relationship between the two. Quantitative analysis of the macro elements may elucidate this relationship (Deinum and Dirven, to be published).

Percentage water-soluble carbohydrates. This constituent was affected by light intensity and age, contrary to the effect on nitrate content, showing increased concentrations with increasing light intensity and age. The effect of varying nitrogen supply is very clear. The effect of temperature was not significant in this experiment. However, higher 
concentrations were found with higher temperatures in the former experiment (Deinum and Dirven, 1967) and in the work of Wilson and Ford with tropical grasses (1971), contrary to the general findings in temperate grasses (Alberda, 1965; Deinum, 1966a, 1966b).

The percentage water-soluble carbohydrates was usually low like in most grasses in tropical areas, but in some treatments it exceeded $10 \%\left(\mathrm{~T}_{1} \mathrm{~L}_{3}\right.$ and $\mathrm{T}_{3} \mathrm{~L}_{3}$ after 5 weeks). In these cases there was still a rather high concentration of nitrate, suggesting that Congo grass may accumulate more nitrate than some other grasses (Dirven and Dejnum, 1972, in preparation).

Percentage of crude fibre. This percentage increased appreciably with age in agreement with many other findings. It increased as well with higher temperatures, but was considerably depressed by light intensity, suggesting opposit effects on digestibility. These results indicated fair relationships with tiller weight and leaf $\%$, but light intensity and temperature had some effect on these relationships. This will be discussed later in this paper.

Percentage rest. This percentage is composed of organic acids, fats, hemicellulose, lignin and starch. Light intensity was the sole factor showing a significant effect and this positive effect was as large as in the former experiment (Deinum and Dirven, 1967). The percentage of organic acids (C-A, de Wit et al., 1964) was not affected by light intensity (Deinum and Dirven, to be published). Furthermore, $\%$ lignin and hemicellulose are usually well related to the $\%$ cf $(\approx 0 \%$ cellulose) suggesting these constituents should be decreased by higher light intensity. This might indicate the presence of high quantities of starch at high light intensities. However starch analyses were negative, but it is not clear whether the correct procedure was used. On the contrary the high nitrate concentrations will prevent the accumulation of starch. Maybe in this experiment higher light intensities increased $\%$ hemicellulose, like in a few other experiments (Deinum, 1969; Deinum et al., 1968).

\section{Relationship between $\%$ crude fibre and morphological characters}

It will be evident from the preceding results, that there was a close relationship between chemical and morphological composition in this experiment with varying degrees of stem formation. This is especially apparent in the percentage organic nitrogen and percentage crude fibre. In some instances light intensity and temperature had some effect on this relationship. Because this was suspected, the elaborate separation procedure of leaves and stem was performed. When sufficient material was available both fractions were analysed for crude fibre and the results are presented in the lower part of Table 1.

Percentage crude fibre in leaves of old tillers. Table 1 shows that this percentage was not significantly increased by age under these conditions of constant light intensity and temperature, as suggested in the former paper (Deinum and Dirven, 1971). Light intensity decreased $\%$ cf somewhat and temperature increased it somewhat. $\%$ crude fibrc of leaves of the new tillers was not significantly lower than that of old tiller leaves.

Percentage crude fibre of stems of old tillers. Contrary to $\% \mathrm{cf}$ of leaves the percentage of stems increased appreciably with age, whereas light intensity had a great negative and temperature a great positive effect on $\% \mathrm{cf}$ of stems. They were about two to three 

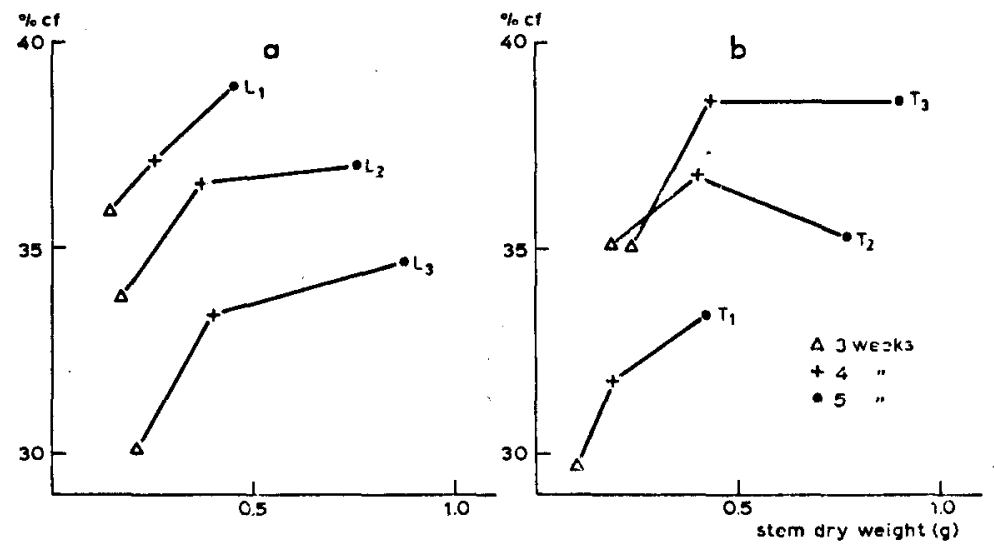

Fig. 1. Effect of stem weight of Congo grass on percentage crude fibre of stems; a. at different light intensities; $b$, at different temperatures.

times as high as in leaves. These effects are associated with stem weight in Fig. 1, showing that at a certain stem weight $\%$ cf was about $6 \%$ units lower at high than at low light intensity. In the same way high temperature gave a higher crude fibre content at a certain stem weight than low temperature. A similar effect of light intensity on the relationship beween $\%$ cf and stem weight was found in the new tillers. However, the $\%$ cf was about $2 \%$ higher at the same stem weight in the new than in the old tillers. This may be caused by the lower light intensity, because the new tillers were growing in the shade of the old ones.

Consequently these results imply that light intensity and temperature definitely affect the relationship between chemical and morphological composition as far as $\%$ cf is concerned.

Considering all results of this experiment, it is evident that age and climate influence forage quality, partly because of their effects on morphological composition, partly due to their effects on the composition of the different morphological fractions.

Moreover it is clear that forage quality is decreased by higher temperature indicating that the high temperature of tropical areas may be the major cause of the poor quality of tropical grasses, as predicted from results on temperate grasses.

\section{Acknowledgments}

The authors wish to express their gratitude to Mr Koop Wind and Mr Klaas van der Laan for their special care in assisting with the experiment and for the claborate morphological separation work and the calculations.

\section{References}

Alberda, Th., 1965. The influence of temperature, light intensity and nitrate concentration on drymatter production and chemical composition of Lolium perenne L. Neth. J. agric. Sci. 13, $355-360$. 
Burg, P. F. J. van, 1962 Interne stikstofbalans, produktie van droge stof en veroudering bij gras. Versl. landbouwk. Onderz. 68.12, pp. 131.

Deinum, B., 1966a. Climate, nitrogen and grass. 1. Research into the influence of light intensity, temperature, water supply and nitrogen on the production and chemical composition of grass. Meded. Landb. Hogesch. Wageningen 66-11, pp. 91.

Deinum, B., 1966b. Influence of some climatological factors on the chemical composition and feeding value of herbage. Proc. 10th Int. Grasslnd Congr. (Helsinki): 415-418.

Deinum, B., 1969. Measurement of forage quality and the assessment of maximum crop yield. Tour report. Meded. Afdeling Landbouwplantenteelt en Graslandcultuuur nr. 15, pp. 40.

Deinum, B. \& J. G. P. Dirven, 1967. Een oriënterende proef omtrent de invloed van licht en temperatuur op opbrengst en chemische samenstelling van Brachiaria ruziziensis Germain et Everard. Surin. Landb. 15, 1-10.

Deinum, B. \& J. G. P. Dirven, 1971. Climate, nitrogen and grass. 4. The effect of age on chemical composition and in vitro digestibility of maize (Zea mays L.) and tall fescue (Festuca arundinacea Schreb.). Neth. J, agric. Sci, 19: 264-272.

Deinum, B., A. J. H. van Es \& P. J. Van Soest, 1968. Climate, nitrogen and grass. 2. The influence of light intensity, temperature and nitrogen on vivo digestibility of grass and the prediction of these effects from some chemical procedures. Neth. J. agric. Sci. 16: 217-223.

Hylton, L. O., D. Williams, A. Ulrich \& D. R. Cornelius, 1964. Critical nitrate levels for growth of Italian ryegrass. Crop Sci. $4,16-19$.

Wilson, J. R. \& C. W. Ford, 1971. Temperature influences on the growth, digestibility and carbohydrate composition of two tropical grasses, Panicum maximum var. trichoglume and Setaria sphacelata, and two cultivars of the temperate grass Lolium perenne. Aust. J. agric. Res. 22: $563-572$.

Wit, C. T. de, W. Dijkshoorn \& J. C. Noggle, 1963. Ionic balance and growth of plants. Versl. landbouwk Onderz. 69.15, pp. 68. 